\title{
Surgical Treatment of Intestinal Endometriosis: Outcomes of Three Different Techniques
}

\section{Tratamento cirúrgico de endometriose intestinal: resultados de três técnicas operatórias}

\author{
Fernando Bray-Beraldo ${ }^{1}$ Ana Maria Gomes Pereira \\ Reginaldo Guedes Coelho Lopes ${ }^{2}$ \\ ${ }^{1}$ Gastroenterology Surgery Service, Hospital do Servidor Público \\ Estadual, São Paulo, SP, Brazil \\ ${ }^{2}$ Ginecology Service, Hospital do Servidor Público Estadual, \\ São Paulo, SP, Brazil
}

Rev Bras Ginecol Obstet 2018;40:390-396.

\begin{abstract}
Cláudia Gazzo ${ }^{2}$ Marcelo Protásio Santos ${ }^{1}$
\end{abstract}
\begin{abstract}
Address for correspondence Fernando Bray-Beraldo, MSc, Hospital do Servidor Público Estadual, Rua Pedro de Toledo 1800, $14^{\circ}$ andar, Serviço de Gastrocirurgia - Vila Clementino, 04039-000, São Paulo, SP, Brasil (e-mail: drfernandobrayberaldo@gmail.com).
\end{abstract}

\begin{abstract}
Objective To outline the demographic and clinical characteristics of patients with deep intestinal endometriosis submitted to surgical treatment at a tertiary referral center with a multidisciplinary team, and correlate those characteristics with the surgical procedures performed and operative complications.

Methods A prospective cohort from February 2012 to November 2016 of 32 women with deep intestinal endometriosis operations. The variables analyzed were: age; obesity; preoperative symptoms (dysmenorrhea, dyspareunia, acyclic pain, dyschezia, infertility, urinary symptoms, constipation and intestinal bleeding); previous surgery for endometriosis; Enzian classification; size of the intestinal lesion; and surgical complications.

Results The mean age was $37.75( \pm 5.72)$ years. A total of 7 patients $(22 \%)$ had a prior history of endometriosis. The mean of the largest diameter of the intestinal lesions identified intraoperatively was of $28.12 \mathrm{~mm}( \pm 14.29 \mathrm{~mm})$. In the Enzian classification, there was a predominance of lesions of the rectum and sigmoid, comprising 30 cases (94\%). There were no statistically significant associations between the predictor variables and the outcome complications, even after the multiple logistic regression analysis. Regarding the size of the lesion, there was also no significant correlation with the outcome complications ( $p=0.18 ; 95 \%$ confidence interval [95\% Cl]:0.94-1.44); however, there was a positive association between grade 3 of the Enzia classification and the more extensive surgical techniques: segmental intestinal resection and rectosigmoidectomy, with a prevalence risk of 4.4 ( $p<0.001 ; 95 \% \mathrm{Cl}: 1.60-12.09)$.
Keywords
- endometriosis
- laparoscopy
- colorectal surgery Conclusion The studied sample consisted of highly symptomatic women. A high prevalence of deep infiltrative endometriosis lesions was found located in the rectum and sigmoid region, and their size correlated directly with the extent of the surgical resection performed.
\end{abstract}

received

October 17, 2017

accepted

April 16, 2018

published online

June 27, 2018
Copyright $\odot 2018$ by Thieme Revinter

Publicações Ltda, Rio de Janeiro, Brazil
License terms

(c) (i) $\ominus$ (\$) 10.1055/s-0038-1660827. ISSN 0100-7203. 


\section{Resumo}

\section{Palavras-Chave \\ - endometriose \\ - laparoscopia \\ - cirurgia colorretal}

Objetivo Delinear as características das pacientes portadoras de endometriose profunda intestinal submetidas a tratamento cirúrgico em centro de referência com equipe multidisciplinar, e correlacionar tais achados com a extensão de doença e com os procedimentos cirúrgicos realizados.

Métodos Tratamento cirúrgico no período de fevereiro de 2012 a novembro de 2016 em 32 mulheres portadoras de endometriose profunda intestinal. Variáveis analisadas: idade; obesidade; queixas pré-operatórias: dismenorreia, dispareunia, dor acíclica, disquezia, sangramento uterino anormal, infertilidade, sintomas urinários, constipação, e sangramento intestinal; cirurgia prévia para tratamento de endometriose profunda; classificação de Enzian; técnica cirúrgica aplicada; tamanho da lesão intestinal; e complicações operatórias.

Resultados A média de idade foi de $37,75( \pm 5,72)$ anos. Um total de 7 (22\%) pacientes tinha histórico de abordagem prévia da endometriose. A média do maior diâmetro das lesões intestinais foi de $28,12 \mathrm{~mm}( \pm 14,29 \mathrm{~mm})$. Na classificação de Enzian, houve predomínio das lesões da região de reto ou retossigmoide no compartimento posterior, num total de 30 casos (94\%). Não foi observada associação estatística significativa entre as variáveis preditivas e o desfecho da complicação, mesmo após análise de regressão logística múltipla. Quanto ao tamanho da lesão, também não houve correlação significativa com o desfecho complicação $(p=0,18$; intervalo de confiança de 95\% [IC95\%]: 0,94-1,44). No entanto, Houve associação positiva entre o grau 3 da classificação de Enzian e a técnica cirúrgica mais extensa: ressecção intestinal segmentar e retossigmoidectomia, com risco de prevalência de 4,4 ( $p=0,00003$; IC95\%: 1,60-12,09).

Conclusão A amostra populacional estudada foi constituída de mulheres muito sintomáticas. Foi encontrada prevalência alta de lesões de endometriose infiltrativa profunda localizadas em região de retossigmoide, e seu tamanho correlacionou-se diretamente com a extensão da ressecção cirúrgica realizada.

\section{Introduction}

Characterized by the presence of active endometrial cells outside the uterine cavity, endometriosis is the second most common benign gynecological condition in women of reproductive age, affecting $7-15 \%$ of the female population., Generally, there is a delay in time between the first symptoms and the diagnosis of endometriosis, approximately seven years, which is caused not only by symptoms of a nonspecific nature, but also by the lack of clinical suspicion and adequate interaction between different non-gynecological specialties. ${ }^{2-4}$

The pelvis is the most affected site; however, there may be endometrial lesions in virtually any part of the abdomen, and even in other extrapelvic sites. ${ }^{1,2,5,6}$ In deep manifestations of the disease, defined as infiltration beyond $5 \mathrm{~mm}$ of the peritoneum, ${ }^{7}$ some authors estimate the frequency of deep infiltrative endometriosis (DIE) at $5-12 \%$ of women

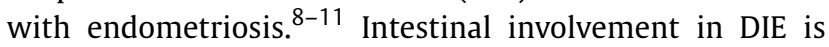
frequent; however, its prevalence is controversial, with a description of 5 to $30 \%$ of occurrence in the intestine ${ }^{9,12,13}$ depending on the accuracy of the diagnostic methods used and the interaction between the clinical and surgical teams in specialized services. While more than $90 \%$ of intestinal localization concern the rectum and distal sigmoid colon. 8,14

Colorectal impairment impacts the quality of life of patients, mainly due to complaints of pain, and it causes alterations in bowel function. ${ }^{11}$ Surgical treatment is currently considered the first option in symptomatic patients with invasive intestinal compromise, as it leads to lasting relief of symptoms and improvement in quality of life. ${ }^{1,4,8}$

A multidisciplinary team with experience in laparoscopic pelvic surgery and a precise preoperative diagnosis are fundamental for surgical planning. Tailored surgery, choosing the most appropriate technique for each patient, aims at better results in symptomatology, avoiding extensive, sometimes unnecessary, procedures. ${ }^{8,11}$ Different techniques of intestinal resection were used with variable results concerning quality of life and relapse of the disease, and the most widespread are rectosigmoidectomy, segmental and discoid resection, as well as shaving. ${ }^{15-18}$

The objective of this study was to delineate the characteristics of the patients with DIE submitted to surgical treatment in a reference center with a multidisciplinary team, and to correlate the findings with the extent of the disease, the surgical procedures performed, and the complications observed. 


\section{Methods}

The present study is a partial results report of a bigger research that consists of a long-term follow-up that analyzes clinical and surgical outcomes of patients that underwent surgical treatment for intestinal endometriosis, approved by the Ethics Committee of the Institute of Medical Assistance of the Hospital do Servidor Público Estadual of the city of São Paulo. The method used in this study complied with the criteria of Resolution no. 466/12 on Ethics in Research with Human Beings of the Brazilian National Health Council, under CAAE no. 50405215.1.0000.5463.

This prospective cohort consists of 32 women, aged over 18 years, with a diagnosis of deep intestinal endometriosis. All surgical procedures were performed at the Hospital do Servidor Público Estadual of the city of São Paulo by an experienced multidisciplinary team of the Gastroenterology Surgery and Gynecology Services, in the period from February 2012 to November 2016.

The preoperative complementary propedeutics consisted of rigid rectosigmoidoscopy, nuclear magnetic resonance of the pelvis, and transvaginal pelvic ultrasonography with bowel preparation. ${ }^{19}$

The Enzian classification ${ }^{20,21}$ was adopted to describe the extent of the endometriosis identified during the intraoperative period; since it was used exclusively to describe the surgical findings, it did not interfere with the surgical judgment. This classification enables a good morphological description of deep invasive endometriosis through the denomination of the affected compartments and the size of the lesion. $^{20,21}$

Colonic retrograde preparation was used on the eve of the procedure with glycerin and prophylactic intraoperative antibiotic with second generation cephalosporin (Cefoxitin, Pfizer Inc., New York, NY, US). The laparoscopic access was performed through a $10-\mathrm{mm}$ umbilical trocar and 30 degree laparoscope. The access trocars had $12 \mathrm{~mm}$ and $5 \mathrm{~mm}$ on the right flank, and $5 \mathrm{~mm}$ on the left flank. In some cases, a 5-mm suprapubic auxiliary puncture was performed.

The surgical management of each technique was based on endometriosis foci patterns such as length, single or multiple lesions, and degree of bowel infiltration, and a complete resection of all macroscopic diseases was performed. When segmental resection or rectosigmoidectomy were performed, colorectal anastomosis was performed using a double stapling technique and extraction of the surgical specimen through a Pfannenstiel incision (-Fig. 1). In the full-thickness discoid resections, the surgical specimen was removed through circular stapling, which had a diameter of $33 \mathrm{~mm}$. In all "shaving" resections, the intestinal muscular layer was sutured with Caprofyl 3.0 (Ethicon Inc., Bridgewater, NJ, US).

The variables analyzed were: age; obesity; preoperative symptoms (dysmenorrhea, dyspareunia, acyclic pain, dyschezia, infertility, urinary symptoms, constipation and intestinal bleeding); previous surgery for endometriosis; Enzian classification; size of the intestinal lesion; and surgical complications. Note that the size of the endometriotic lesion was measured at the operation room just after the specimen was resected.

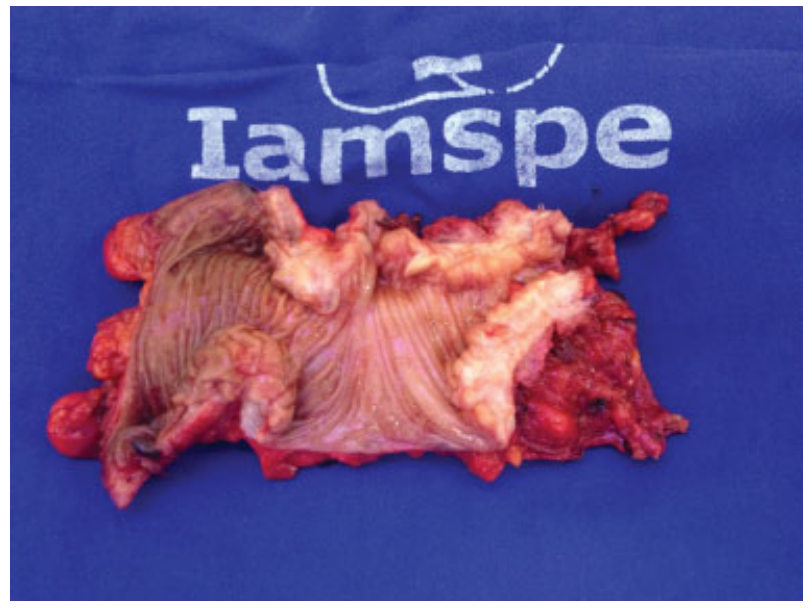

Fig. 1 Surgical specimen after rectal segmental resection.

In the data analysis, the arithmetic mean and standard deviation were used when there was a normal distribution of the sampl,e and median and quartiles were used when the data were not parametric. The frequency distributions of the categorical variables were also observed and reported as absolute numbers followed by percentages: $\mathrm{n}(\%)$. The statistical program used was the R (R Foundation for Statistical Computing, Vienna, Austria) software, version 3.3.1, for the multiple regression analysis, to try to detect a correlation between predictor variables and outcomes. In the modeling of the regressions, the variables were initially selected by a significance cut-off point of $\leq 0.20$ to provide a more comprehensive range of possible predictor variables. The final statistical significance level was set at $p<0.05$, corresponding to a $95 \%$ confidence interval $(95 \% \mathrm{CI})$.

\section{Results}

In total, 32 women with DIE were analyzed, with a mean age of $37.75( \pm 5.72)$ years, ranging from 27 to 50 years. The distribution of the frequency of the symptoms reported prior to the surgical treatment is shown in - Table 1.

No patient complained of intestinal bleeding. All were on steroid hormone medication for induction of amenorrhea, and $14(45.16 \%)$ had used a gonadotropin-releasing hormone $(\mathrm{GnRH})$ analogue during the preoperative clinical treatment.

Table 1 Distribution of the frequency of preoperative symptoms

\begin{tabular}{|l|l|}
\hline Symptoms & $\mathbf{n}(\%)$ \\
\hline Dysmenorrhea & $27(84.38)$ \\
\hline Dyspareunia & $22(68.76)$ \\
\hline Acyclic pelvic pain & $20(62.50)$ \\
\hline Dyschezia & $16(50.00)$ \\
\hline Intestinal constipation & $16(50.00)$ \\
\hline Infertility & $11(34.38)$ \\
\hline Abnormal uterine bleeding & $5(15.63)$ \\
\hline
\end{tabular}

Abbreviations: n, absolute number; \%, percentage. 
All patients underwent surgery after the failure of the clinical treatment to control the pelvic pain.

In the preoperative evaluation, 11 (34.38\%) patients presented associated diseases, of different natures, without clinical repercussion. Regarding the previous surgery, 7 (21.88\%) women had a prior history of endometriosis, all without intestinal intervention.

The distribution pattern of intestinal lesions was 30 (93.75\%) in the middle and high rectum, $4(12.50 \%)$ in the sigmoid colon, $3(9.37 \%)$ in the appendix, and $1(3.12 \%)$ in the terminal ileum. The mean of the largest diameter of the intestinal lesions was of $28.12 \mathrm{~mm}( \pm 14.29 \mathrm{~mm})$, with a median of $27.5 \mathrm{~mm}$ (15$40 \mathrm{~mm}$ ). It is important to mention that the accuracy of the preoperative radiologic exams was satisfactory, with the exception of the lesions in the appendix and ileum, which were diagnosed only during the surgical intervention.

After the multiple linear regression analysis, there was no statistically significant correlation between the epidemiological data or the symptoms and the size of the DIE lesion (-Table 2).

The staging of the infiltrative endometriotic disease through the Enzian classification is shown in - Table 3, with a predominance of lesions in the rectum or rectosigmoid region in the posterior compartment, comprising 30 (93.75\%) cases. In 13 (40.62\%) women, there was an association of ovarian cystic endometriosis, and 4 (12.5\%) cases presented association with bladder lesions. A total of 4 (12.5\%) other cases presented involvement of other intestinal segments: 1 (3.12\%) in the ileum, and $3(9.37 \%)$ in the appendix. The Enzian classification refers to lesions as " $\mathrm{A}$ " when they affect the region of the rectovaginal septum or

Table 2 Multiple linear regression analysis for correlation of epidemiological characteristics and symptoms with DIE lesion size

\begin{tabular}{|l|l|l|l|}
\hline Variables & $\begin{array}{l}\text { Initial OR } \\
(95 \% \mathrm{Cl})\end{array}$ & $\begin{array}{l}\text { Adjusted OR } \\
(95 \% \mathrm{Cl})\end{array}$ & $\begin{array}{l}\text { Adjusted } \\
\text { p-value } \\
\text { (Wald test) }\end{array}$ \\
\hline Infertility & $\begin{array}{l}13.00 \\
(3.30-22.69)\end{array}$ & $\begin{array}{l}9.46 \\
(-1.38-20.30)\end{array}$ & 0.08 \\
\hline Dyschezia & $\begin{array}{l}9.67 \\
(-0.23-19.52)\end{array}$ & $\begin{array}{l}6.06 \\
(-3.92-16.04)\end{array}$ & 0.22 \\
\hline $\begin{array}{l}\text { Abnormal } \\
\text { uterine } \\
\text { bleeding }\end{array}$ & -10.81 & -5.66 & 0.40 \\
$(-24.69-3.06)$ & $(-19.35-8.02)$ & \\
\hline
\end{tabular}

Abbreviations: 95\%Cl, 95\% confidence interval; DIE, deep infiltrative endometriosis; $\mathrm{OR}$, odds ratio.

Table 3 Distribution of lesion location through the Enzian classification

\begin{tabular}{|l|l|l|l|l|}
\hline Lesion size $(\mathbf{c m})$ & \multirow{2}{*}{ Degree } & \multicolumn{3}{|c|}{ Affected area } \\
\cline { 3 - 5 } & & A & B & C \\
\hline$<1$ & 1 & 0 & 0 & 0 \\
\hline 1 to 3 & 2 & 1 & 0 & 17 \\
\hline$>3$ & 3 & 1 & 0 & 13 \\
\hline
\end{tabular}

Table 4 Distribution of surgical techniques

\begin{tabular}{|l|l|}
\hline Surgical technique & $\mathbf{n}(\%)$ \\
\hline "Shaving" of the rectum & $14(43.75)$ \\
\hline Segmental resection of the rectum & $9(28.13)$ \\
\hline Discoid resection of the rectum & $6(18.75)$ \\
\hline Rectosigmoidectomy & $3(9.38)$ \\
\hline Appendectomy & $3(9.37)$ \\
\hline "Shaving" of the ileum & $1(3.12)$ \\
\hline
\end{tabular}

Abbreviations: $\mathrm{n}$, absolute number; \%, percentage.

vagina; "B" when they reach the retrocervical region and/or uterosacral ligaments; and " $\mathrm{C}$ " when the involvement is intestinal infiltration of the rectum or rectosigmoid. In addition, it separates lesion size into $<1 \mathrm{~cm}, 1$ to $3 \mathrm{~cm}$, and $>3 \mathrm{~cm}$, creating a visual staging of the pelvic involvement of deep endometriosis.

- Table 4 presents the distribution of the surgical techniques used for the resection of the intestinal lesions. All procedures were performed exclusively through laparoscopy. There was no requirement for ureteral resections, with 4 (12.50\%) resections of nodules in the vesicouterine recess. In $1(3.12 \%)$ patient, vaginal dome resection and rectum wall "shaving" were performed.

Hospital discharge occurred after the return of intestinal peristalsis and good acceptance of a solid oral diet, with an approximate hospitalization time of 5 to 7 days, except for 1 (3.12\%) patient. This case evolved with colorectal anastomosis fistula after segmental resection of the rectum, which was treated with antibiotic therapy. A total of 1 (3.12\%) other patient required reoperation due to the manifestation of a rectovaginal fistula on the 8th postoperative day. A laparoscopic derivative ileostomy loop approach was performed, followed after six weeks by resection of the fistulated anastomosis of the vagina, vaginal raffia, and colorectal reanastomosis. After one month, the intestinal transit was restored. The cases of the anastomotic fistula and rectovaginal fistula were defined as "complications."

No statistically significant associations were observed between possible predictor variables and the "complication" outcome, even after the multiple logistic regression analysis. There was also no significant correlation with increased risk for "complication" in lesions greater than $30 \mathrm{~mm}$ (Enzian grade 3$),(p=0.18 ; 95 \%$ CI: $0.94-1.44)$. There was a positive association between grade 3 of the Enzian classification and the most extensive surgical techniques: segmental intestinal resection and rectosigmoidectomy, with a prevalence risk of 4.4 ( $p=0.00003$; 95\%CI: 1.60-12.09).

Multiple logistic regression analysis was applied to the following variables: number of pregnancies, number of births, complaints of constipation, dyschezia and infertility, and size of the lesion in millimeters. A statistically significant association was found between lesion size and the outcome of bowel resection adjusted for the presence of dyschezia and previous surgery, as seen in - Table 5 . 
Table 5 Multiple logistic regression analysis for the correlation with the segmental resection surgical technique

\begin{tabular}{|l|l|l|l|}
\hline Variables & $\begin{array}{l}\text { Initial OR } \\
(95 \% \mathrm{Cl})\end{array}$ & $\begin{array}{l}\text { Adjusted OR } \\
(95 \% \mathrm{CI})\end{array}$ & $\begin{array}{l}\text { Adjusted } \\
\boldsymbol{p} \text {-value } \\
\text { (Wald Test) }\end{array}$ \\
\hline $\begin{array}{l}\text { Size of } \\
\text { the lesion }\end{array}$ & $\begin{array}{l}1.17 \\
(1.05-1.3)\end{array}$ & $\begin{array}{l}1.16 \\
(1.04-1.30)\end{array}$ & 0.007 \\
\hline Dyschezia & $\begin{array}{l}5.57 \\
(1.13-27.52)\end{array}$ & $\begin{array}{l}3.09 \\
(0.36-26.43)\end{array}$ & 0.303 \\
\hline $\begin{array}{l}\text { Previous } \\
\text { surgery }\end{array}$ & $\begin{array}{l}0.37 \\
(0.06-2.19)\end{array}$ & $\begin{array}{l}0.79 \\
(0.0-8.84)\end{array}$ & 0.846 \\
\hline
\end{tabular}

Abbreviations: 95\% Cl, 95\% confidence interval; OR, odds ratio.

\section{Discussion}

Intestinal infiltrative endometriosis can be managed with clinical follow-up as long as the patient remains asymptomatic and the intestinal lesion is not stenotic or bleeding. Although some women remain oligosymptomatic or without complaints, many persist with complaints of intense pain, which has an important impact on their personal and professional lives. ${ }^{11}$ The most frequently encountered symptoms are dysmenorrhea and dyspareunia, which corroborate with the findings of the present series of cases, in which the percentages were $84 \%$ and $69 \%$ respectively. Very similar data were found in a series of cases previously observed in our service $^{22}$ and in a large study with more than 3,000 operated women, which found $95 \%$ of dysmenorrhea and $87 \%$ of dyspareunia. 16

There is a wide range of drug options for symptom control; however, the decision to perform surgical treatment with resection of the endometriotic lesions proved to be the therapeutic option with better results in the control of symptoms and for quality of life. ${ }^{23,24}$ In addition, a significant number of intestinal lesions have a fibrotic component that does not respond to hormonal suppression. ${ }^{25}$

In order to stage the endometriosis, the most commonly used classification system is from the American Society for Reproductive Medicine. ${ }^{26}$ However, there are limitations with respect to this classification, especially when involving retroperitoneal structures and non-gynecological pelvic organs. Therefore, the Enzian classification was chosen, which enables the description of infiltrative lesions in the retrocervical region, rectovaginal septum, intestinal structures, bladder, and ureter. ${ }^{20,21}$ In all cases in the present study there was intestinal involvement, with a predominance of infiltrative disease in compartment $\mathrm{C}$ of the classification (rectal interface with retrocervical and sigmoid region), corresponding to $93.75 \%$ of the lesions with $\sim 28 \mathrm{~mm}$ of extension. These results differ from those in the literature regarding the main site of infiltrative disease; in the literature, there is a higher frequency of lesions located in compartment $B$ (region of the uterosacral and cardinal ligaments). ${ }^{21}$ This divergence may be the result of a selection bias in our series of cases due to referral for treatment in conjunction with a coloproctologist, suggesting intestinal involvement, or it may be due to the natural diffi- culty to precisely define the location of the lesion, since the compartments (A, B, and C) of this classification are anatomically contiguous. Although there is some disagreement in the application of the Enzian classification, this model seems to be the most adequate and functional, providing a postoperative description of DIE lesions.

The techniques used to treat the intestinal lesions conformed to the criteria to try to avoid large intestinal resections, within the possibilities of the size of the lesion, while maintaining the radicality necessary to treat the symptomatic disease. $^{16,27-29}$

In $44 \%$ of the cases, it was possible to carry out the excision of lesions by means of "shaving," precisely because those lesions restrict themselves to the more superficial muscular layer of the intestine. In $19 \%$ of the lesions with involvement beyond the muscular layer and up to $30 \mathrm{~mm}$, a discoid resection of the rectum was performed. In infiltrative lesions more than $30 \mathrm{~mm}$ in size, there was a need for segmental resection of the rectum or rectosigmoidectomy (in 37\% of the cases), which was demonstrated by the positive correlation observed in the analysis between the degree of injury in the Enzian classification and the type of intestinal resection performed. Multiple regression showed that the larger the lesion size, the greater the association with the use of wider intestinal resection, so that perhaps earlier diagnoses of minor lesions would enable the use of less extensive techniques, avoiding aggressive dissections and short- and long-term complications.

Despite evidence on the improvement of symptoms after surgical treatment for intestinal endometriosis, there is no consensus about the superiority of one resection technique over another. ${ }^{16,30-33}$ In addition, it is worth remembering that the proposed surgical treatment is always accompanied by risks of serious complications such as colorectal anastomosis fistula, ureteral lesion, rectovaginal fistula, and vascular lesions. $6,31,34$

In the present study, there was only $1(3.12 \%)$ case of a major complication that required reoperation. A rectovaginal fistula occurred due to the probable involvement of the posterior wall of the vagina in the stapling of the colorectal anastomosis during the segmental rectal resection. The occurrence of complications was low, with only two cases being reported, and there was no case of surgical conversion to the laparotomic technique; however, the number of cases in this series is too small for us to make adequate comparisons with other reports in the literature. In addition, it was not possible to observe a statistical correlation between the variables and complications studied.

Our multidisciplinary team does not routinely perform ileostomy after colorectal anastomosis. There was a need for ileostomy in a protective loop after segmental rectal resection in only one patient, due to the positive test for anastomotic leakage, both with air and methylene blue. Although most colorectal anastomoses are low, it is not necessary to indicate a systematic derivative stoma similar to that performed in low anterior rectosigmoidectomy in the treatment of colorectal cancer, as the profile of the sample is completely different, composed of young women without severe comorbidities and well-nourished; however, this practice challenges those of other authors. ${ }^{6}$ 
The distribution pattern of infiltrative endometriotic disease greatly distorts the pelvic anatomy, which makes it essential to have an in-depth knowledge of the anatomical planes and dissemination patterns of the disease, as well as a multidisciplinary team with experience in laparoscopic pelvic surgery to perform the treatment with the maximum functional preservation of the pelvic organs.

The authors arere aware that this study has a major limitation, since the amount of patients enrolled was low, and this directly affects the comparison of the surgical techniques performed. Nevertheless, the cohort is being enlarged, as surgical procedures continue to be performed by our study group, and an ultimate result may be published, as the endpoint established of one hundred patients is achieved.

\section{Conclusion}

The sample was composed of very symptomatic women; however, no symptoms or epidemiological characteristics correlated with the size of the DIE lesions or operative complications. On the other hand, the size of the lesions correlated directly with the extent of surgical resection performed, but not with the operative complications.

\section{Contributions}

Bray-Beraldo F, Pereira AMG, Gazzo C, Santos MP and Lopes RGC contributed with the conception and design, data collection and analysis, interpretation of data, writing of the article, critical review of the intellectual content, and final approval of the version to be published.

\section{Conflicts of Interest}

The authors have no conflicts of interest to disclose.

\section{References}

1 Klugsberger B, Shamiyeh A, Oppelt P, Jabkowski C, Schimetta W, Haas D. Clinical outcome after colonic resection in women with endometriosis. BioMed Res Int 2015;2015(15):514383

2 Alkatout I, Egberts JH, Mettler L, et al. Interdisciplinary diagnosis and treatment of deep infiltrating endometriosis. Zentralbl Chir 2016;141(06):630-638. Doi: 10.1055/s-0034-1383272

3 Arruda MS, Petta CA, Abrão MS, Benetti-Pinto CL. Time elapsed from onset of symptoms to diagnosis of endometriosis in a cohort study of Brazilian women. Hum Reprod 2003;18(04):756-759

4 Santos TMV, Pereira AMG, Lopes RGC, Depes DdeB. Lag time between onset of symptoms and diagnosis of endometriosis. Einstein (Sao Paulo) 2012;10(01):39-43. Doi: 10.1590/S167945082012000100009

5 Prystowsky JB, Stryker SJ, Ujiki GT, Poticha SM. Gastrointestinal endometriosis. Incidence and indications for resection. Arch Surg 1988;123(07):855-858

6 Bachmann R, Bachmann C, Lange J, et al. Surgical outcome of deep infiltrating colorectal endometriosis in a multidisciplinary setting. Arch Gynecol Obstet 2014;290(05):919-924. Doi: 10.1007/ s00404-014-3257-x

7 Cornillie FJ, Oosterlynck D, Lauweryns JM, Koninckx PR. Deeply infiltrating pelvic endometriosis: histology and clinical significance. Fertil Steril 1990;53(06):978-983. Doi: 10.1016/S00150282(16)53570-5
8 Abrão MS, Petraglia F, Falcone T, Keckstein J, Osuga Y, Chapron C. Deep endometriosis infiltrating the recto-sigmoid: critical factors to consider before management. Hum Reprod Update 2015;21 (03):329-339. Doi: 10.1093/humupd/dmv003

9 Chapron C, Fauconnier A, Vieira M, et al. Anatomical distribution of deeply infiltrating endometriosis: surgical implications and proposition for a classification. Hum Reprod 2003;18(01):157-161

10 Neme RM, Schraibman V, Okazaki S, et al. Deep infiltrating colorectal endometriosis treated with robotic-assisted rectosigmoidectomy.JSLS 2013;17(02):227-234. Doi: 10.4293/108680813 × 13693422521836

11 Wolthuis AM, Meuleman C, Tomassetti C, D'Hooghe T, de Buck van Overstraeten A, D'Hoore A. Bowel endometriosis: colorectal surgeon's perspective in a multidisciplinary surgical team. World $\mathrm{J}$ Gastroenterol 2014;20(42):15616-15623. Doi: 10.3748/wjg.v20. i42.15616

12 Seracchioli R, Poggioli G, Pierangeli F, et al. Surgical outcome and long-term follow up after laparoscopic rectosigmoid resection in women with deep infiltrating endometriosis. BJOG 2007;114(07): 889-895. Doi: 10.1111/j.1471-0528.2007.01363.x

13 Jerby BL, Kessler H, Falcone T, Milsom JW. Laparoscopic management of colorectal endometriosis. Surg Endosc 1999;13(11): $1125-1128$

14 Bailey HR, Ott MT, Hartendorp P. Aggressive surgical management for advanced colorectal endometriosis. Dis Colon Rectum 1994;37 (08):747-753. Doi: 10.1007/BF02050136

15 Ruffo G, Scopelliti F, Manzoni A, et al. Long-term outcome after laparoscopic bowel resections for deep infiltrating endometriosis: a single-center experience after 900 cases. BioMed Res Int 2014;2014(14):463058

16 Donnez J, Jadoul P, Colette S, Luyckx M, Squifflet J, Donnez O. Deep rectovaginal endometriotic nodules: perioperative complications from a series of 3,298 patients operated on by the shaving technique. Gynecol Surg 2013;10(01):31-40. Doi: 10.1007/s10397-012-0759-z

17 Ceccaroni M, Clarizia R, Bruni F, et al. Nerve-sparing laparoscopic eradication of deep endometriosis with segmental rectal and parametrial resection: the Negrar method. A single-center, prospective, clinical trial. Surg Endosc 2012;26(07):2029-2045. Doi: 10.1007/s00464-012-2153-3

18 Ribeiro PAA, Rodrigues FC, Kehdi IPA, et al. Laparoscopic resection of intestinal endometriosis: a 5-year experience. J Minim Invasive Gynecol 2006;13(05):442-446. Doi: 10.1016/j.jmig.2006.05.010

19 Abrao MS, Gonçalves MO, Dias JA Jr, Podgaec S, Chamie LP, Blasbalg R. Comparison between clinical examination, transvaginal sonography and magnetic resonance imaging for the diagnosis of deep endometriosis. Hum Reprod 2007;22(12): 3092-3097. Doi: 10.1093/humrep/dem187

20 Haas D, Chvatal R, Habelsberger A, Wurm P, Schimetta W, Oppelt P. Comparison of revised American Fertility Society and ENZIAN staging: a critical evaluation of classifications of endometriosis on the basis of our patient population. Fertil Steril 2011;95(05): 1574-1578. Doi: 10.1016/j.fertnstert.2011.01.135

21 Haas D, Wurm P, Shamiyeh A, Shebl O, Chvatal R, Oppelt P. Efficacy of the revised Enzian classification: a retrospective analysis. Does the revised Enzian classification solve the problem of duplicate classification in rASRM and Enzian? Arch Gynecol Obstet 2013; 287(05):941-945. Doi: 10.1007/s00404-012-2647-1

22 Fahmy WM, Lopes RCG, Ramos JFD, et al. Evaluation of the results of surgical treatment of patients with endometriosis of the rectovaginal septum. Rev Bras Ginecol Obstet 2005;27(10): 613-618. Doi: 10.1590/S0100-72032005001000008

23 Dubernard G, Piketty M, Rouzier R, Houry S, Bazot M, Darai E. Quality of life after laparoscopic colorectal resection for endometriosis. Hum Reprod 2006;21(05):1243-1247. Doi: 10.1093/humrep/dei491

24 Bassi MA, Podgaec S, Dias JA Jr, D’Amico Filho N, Petta CA, Abrao MS. Quality of life after segmental resection of the rectosigmoid by laparoscopy in patients with deep infiltrating endometriosis with bowel involvement. J Minim Invasive Gynecol 2011;18(06):730-733. Doi: 10.1016/j.jmig.2011.07.014 
25 Remorgida V, Ferrero S, Fulcheri E, Ragni N, Martin DC. Bowel endometriosis: presentation, diagnosis, and treatment. Obstet Gynecol Surv 2007;62(07):461-470. Doi: 10.1097/01.ogx.0000268688. $55653.5 \mathrm{c}$

26 Revised American Society for Reproductive Medicine classification of endometriosis: 1996. Fertil Steril 1997;67(05):817-821. Doi: 10.1016/S0015-0282(97)81391-X

27 de Almeida A, Fernandes LF, Averbach M, Abrão MS. Disc resection is the first option in the management of rectal endometriosis for unifocal lesions with less than 3 centimeters of longitudinal diameter. Surg Technol Int 2014;24:243-248

28 Meuleman C, Tomassetti C, D'Hoore A, et al. Surgical treatment of deeply infiltrating endometriosis with colorectal involvement. Hum Reprod Update 2011;17(03):311-326. Doi: 10.1093/humupd/ dmq057

29 Roman H, Tuech JJ, Arambage K. Deep rectal shaving followed by transanal disc excision in large deep endometriosis of the lower rectum. J Minim Invasive Gynecol 2014;21(05):730-731. Doi: 10.1016/j.jmig.2014.03.003
30 Fedele L, Bianchi S, Zanconato G, Bettoni G, Gotsch F. Long-term follow-up after conservative surgery for rectovaginal endometriosis. Am J Obstet Gynecol 2004;190(04):1020-1024. Doi: 10.1016/j.ajog.2003.10.698

31 De Cicco C, Corona R, Schonman R, Mailova K, Ussia A, Koninckx P. Bowel resection for deep endometriosis: a systematic review. BJOG 2011;118(03):285-291. Doi: 10.1111/ j.1471-0528.2010.02744.X

32 Acién P, Núñez C, Quereda F, Velasco I, Valiente M, Vidal V. Is a bowel resection necessary for deep endometriosis with rectovaginal or colorectal involvement? Int J Womens Health 2013; 5:449-455. Doi: 10.2147/IJWH.S46519

33 Koh CE, Juszczyk K, Cooper MJW, Solomon MJ. Management of deeply infiltrating endometriosis involving the rectum. Dis Colon Rectum 2012;55(09):925-931. Doi: 10.1097/DCR.0b013e31825f3092

34 Darai E, Ackerman G, Bazot M, Rouzier R, Dubernard G. Laparoscopic segmental colorectal resection for endometriosis: limits and complications. Surg Endosc 2007;21(09):1572-1577. Doi: 10.1007/s00464-006-9160-1 